\title{
SUBMENTAL INTUBATION WITH FLEXIBLE BRONCOSCOPE IN PANFACIAL
} FRACTURE REDUCTION

\author{
C. B. Sridhar ${ }^{1}$, S. Navaneetha Krishnan², V. M. Surya Rao ${ }^{3}$, D. Alagar Raja ${ }^{4}$, K. Shoba ${ }^{5}$
}

\section{HOW TO CITE THIS ARTICLE:}

C. B. Sridhar, S. Navaneetha Krishnan, V. M. Surya Rao, D. Alagar Raja, K. Shoba. "Submental Intubation with Flexible Broncoscope in Panfacial Fracture Reduction". Journal of Evolution of Medical and Dental Sciences 2014; Vol. 3, Issue 72, December 22; Page: 15337-15339, DOI: 10.14260/jemds/2014/4066

\begin{abstract}
Anaesthesia for panfacial fracture reduction is a challenge to anaesthetist. Oral and nasal intubation makes good reduction difficult for the surgeon. Tracheostomy carries high risk. Submental intubation would be the better alternative for short term airway management. Using flexible broncoscope makes even difficult intubations successful.
\end{abstract}

KEYWORDS: Submental intubation, flexible broncoscope, panfacial fractures.

INTRODUCTION: Panfacial fractures involve the skull base, nose, maxilla and mandible. These patients need early open reduction and rigid internal fixation. The biggest challenge in these patients for a anaesthetist is maintaining airway without interfering with the surgeon. Most patients need maxillo-mandibular fixation for adequate reconstruction. Oral intubation is not possible in these cases. Naso endotracheal intubation is contravertial. Cricothyrotomy or tracheostomy are the traditional airway control methods. Submental intubation is an alternative to tracheostomy for shorter airway control. Traditionally submental intubation is done with rigid laryngoscope. However in many patients with mandibular fractures tracheal intubation with rigid laryngoscope would be difficult due to trismus, oedema and altered oral anatomy. Using flexible broncoscope in these patients would lead to succesful tracheal intubation. This can be diverted to submental route later with ease.

CASE REPORT: Four patients who had sustained fracture of maxilla, nasal bones and mandible after road traffic accident were posted for open reduction and internal fixation. Maxillomandibular fixation was a must in these patients. Nasal or oral endotracheal tube was not feasible for good reduction. Submental intubation was considered as an alternative to tracheostomy. Because of oedema and trismus rigid laryngoscope could not be used in these patient. Hence patients were intubated orally, awake with flexible broncoscope with a flexometallic endotracheal tube. Patients were anaesthetised with propofol, atracurium and isoflurane. Submental region was painted and draped. With $2 \%$ lignocaine with adrenaline the incision site was infiltrated. Incision of $1.5 \mathrm{cms}$ were made in the midline posterior to inferior border of mandible.

A curved artery forceps was passed through the submental incision and then through subcutaneous layer, platysma, mylohyoid muscle, sub mucosa and oral mucosa. After entering oral cavity incision was extended parallel to gingiva. Curved artery forceps is opened to widen the passage. The tube connector was removed. With the help of forceps the tube is pulled out of the submental incision and the connector is fixed back. To prevent tube displacement from the larynx, the tube is manually supported in the oral cavity while passing throught the passage. After passing the tube through the passage, its position is confirmed by auscultation and capnography. Tube fixed with stay sutur8ies. All four patients were extubated immediately after the procedure. One patient 


\section{CASE REPORT}

had superficial infection in the submental wound, which healed with antibiotics. The other three patients had no complication.

DISCUSSION: The present techniques for reduction of panfacial fractures require a field free from intubation tube for good results. This makes airway management a great challenge to anaesthetist. Maxillo-mandibular fixation cannot be done with orotracheal tubes. Nasotracheal tube is not advised in patients with nasal bone fractures as it will be difficult to reduce nasal bones with tube in the nose. ${ }^{1}$ Risks of tracheostomy for short term airway management is very high though it is the traditional method. ${ }^{2}$ Retromolar intubation and nasal tube switch techniques are other options which are cumbersome and time consuming. Submental intubation is the next alternative.

Sir Hernandez Altemir in 1986 first introduced submental route for tracheal intubation. This route was more comfortable for the surgeons as they have enough space for reduction and fixation of midfacial and panfacial fractures. ${ }^{3}$ The main complication of this procedure is partial dislodgement of submental tube down into right main bronchus. Extreem care was taken to prevent this with help of skin sutures and circumferential adhesive tapes. Bleeding from the wound, skin infection, arterial desaturation during convertion of oral tube into submental tube, damage to submandibular and submaxillary gland, damage to lingual nerve, fistula formation and scarring are the other complications. However scar of submental intubation is better accepted by patients than tracheostomy scar. ${ }^{4}$

Mandibular fractures are associated with trismus, distortion of oral anatomy and oedema. This makes intubation with direct laryngoscope difficult. Using flexible broncoscope makes awake intubation possible. Flexible bronchoscope has suction port to clear secretions and blood and port for injection of topical anaesthetics. Patient can be intubated orally. After intubation diverting the tube to submental route gives wider access to the surgeon. ${ }^{5}$

\section{REFERENCES:}

1. Shetty MP, Yadav SK, Upadia M. Submental intubations in patients with panfacial injuries: A prospective study. Indian J Anaesth 2011 May-June; 55 (3): 299-304.

2. Kellman RM, Losquadro WD. Comprehensive airway management of patients with maxillofacial trauma. Craniomaxillofac trauma reconstr. Nov 2008; 1 (1): 39-47.

3. Biglioli F, Mortini P, Goisis M, Bardassi A, Boari N. Submental orotracheal intubation: An alternative to tracheostomy in transfacial cranial base surgery. Skull base. Nov 2003; 13 (4): 189-95.

4. Yadav SK, Deo G. Submental intubation including extubation: Airway complications of mandibulomaxillary fixation. Hindawi publishing corporation. Case reports in Anaesthesiology 2012. Article ID 841051. doi.10.1155/2012/841051.

5. Orebaugh SL. Atlas of Airway Management: Techniques and Tools. Philadelphia: Lippincott Williams \& Wilkins; 2007. 


\section{CASE REPORT}

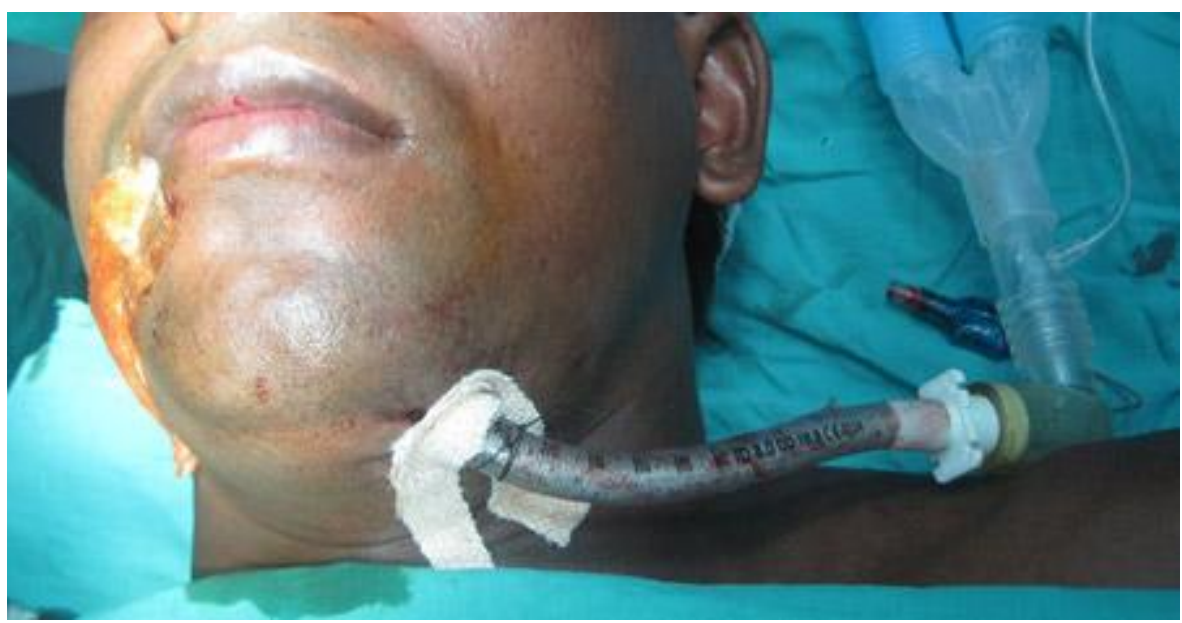

Picture of submental intubation

\section{AUTHORS:}

1. C. B. Sridhar

2. S. Navaneetha Krishnan

3. V. M. Surya Rao

4. D. Alagar Raja

5. K. Shoba

\section{PARTICULARS OF CONTRIBUTORS:}

1. Associate Professor, Department of Anaesthesia, Saveetha Medical College.

2. Associate Professor, Department of Anaesthesia, Saveetha Medical College.

3. Assistant Professor, Department of Plastic Surgery, Saveetha Medical College.

4. Assistant Professor, Department of Plastic Surgery, Saveetha Medical College.
5. Associate Professor, Department of Otorhinolaryngology, Saveetha Medical College.

\section{NAME ADDRESS EMAIL ID OF THE}

\section{CORRESPONDING AUTHOR:}

Dr. Sridhar C. B,

Shanthi Health Centre,

Sembulivarum,

Chennai-600067.

Email: dr.c.b.sree9792@gmail.com

Date of Submission: 08/12/2014.

Date of Peer Review: 09/12/2014.

Date of Acceptance: 15/12/2014.

Date of Publishing: 22/12/2014. 